Biology | Hillary K Tanui, Robert C Luckay \& Ahmed A Hussein

\section{Green cleaning of heavy metals in water}

Many anthropogenic activities
have resulted in pollution of
water with heavy metals, and
pose a huge health risk for
humans and animalls. Some
plants, however, can extract
and accumulate these metals
from soil and water without any
toxic effects. Plant flavonoids
are compounds that have the
chemical ability to bind to
heavy metals. Recent work
by Dr Robert Luckay and
Hillary Tanui (Stellenbosch
University, South Africa), and
Professor Ahmed Hussein
(Cape Peninsula University of
Technology), have identified
specific phytochemicals from
South African plants that bind
to heavy metals in a complex
metal mixture. Their study
presents a novel approach:
using phytochemicals as a
green solution to clean up
heavy metals.

ince industrial times, mankind in technologies that allow easier lifestyles for humans. Yet, this comes at a price: increased anthropogenic activities have led to pollution of our planet, Finding solutions to clen up oun. in a immintons to clean up our mess Africa, pollution of soil and water by heavy metals is a problem resulting from mining and other industrial activities. Consumption of this water is toxic to both the humans and animals that depend on it. Scientists at Stellenbosch University and Cape Peninsula University of Technology in South Africa have been investigating methods by whic heavy metals can be removed from the environment. A recent study by Dr Robert Luckay, Professor Ahmed Hussein and Mr Hillary Tanui, identified specific compounds from South African plants that can bind to heavy metals in complex mixture. Their work provides a polluted waters.

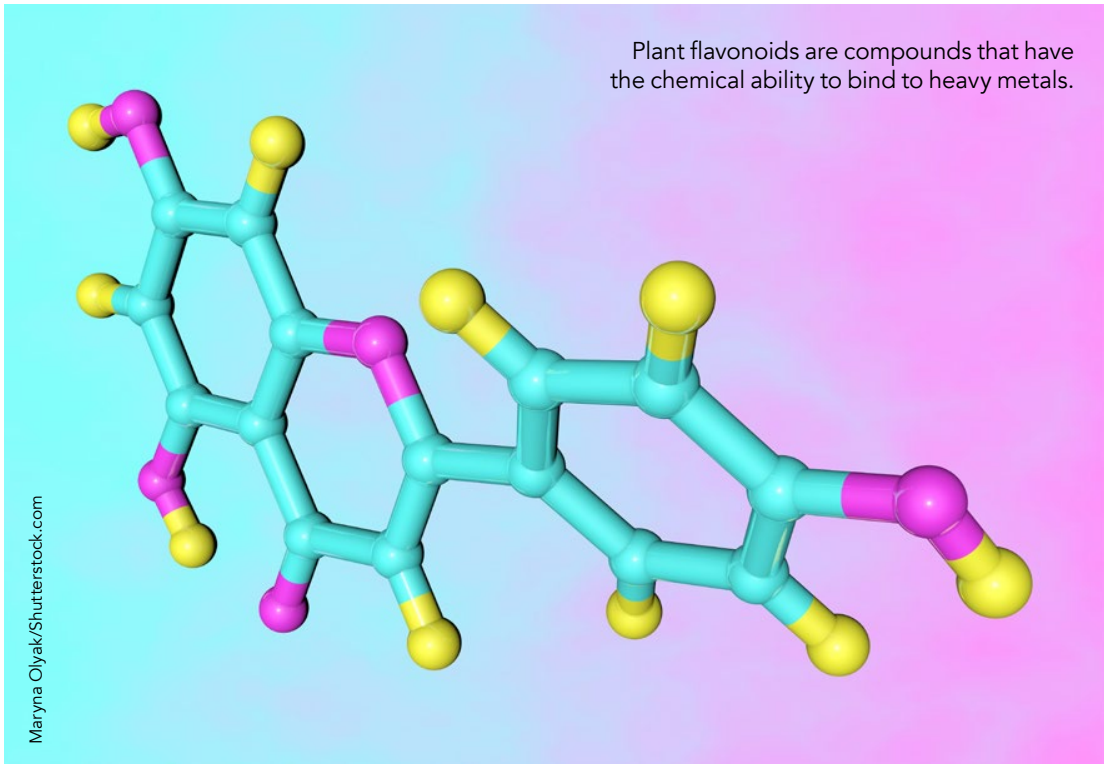

\section{HEAVY-METAL POLLUTION}

potans. In chemical terms, heavy which have a high din the Earth's crust These metals include elem (weight). lead, and cobalt. While trace amounts of some heavy metals are essential for many cellular processes, in excess they are considered toxic, both to organisms and the environment However the use unavoidable. Without them, we would not have mobile phones, pipes, railways, bridges, automobiles, and even certain medicines. Heavy-metal contamination of the environment occurs primarily by human-led activities such as mining, coal-powered stations, use of pesticides in agriculture, industrial wastes, and vehicle emissions. Deposition of excess poor soil and water quality, and due to their long wem persiste for potable water

\section{GREEN HELP}

is now well established that plants can be used to clean up pollutants in the environment, a process called phytoremediation. There are several phytoremediation processes, including phytoextraction - the use of whole plants to accumulate pollutants - however ther is an inherent danger that the metalby animals or humans. Making better use of this biomass, perhaps as fuel, is a viable approach. Other methods are grown under conditions which allow the soil, and the plant accumulates
the heavy metals in its roots: in effect, polled as major environmental

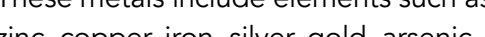
of heavy metals in our everyday life is heavy-metal ions in the soil leads to hyperaccumulating plants are consumed employ rhizofiltration, whereby plants contaminated water to flow through filtering water. An alternative cleaner and heaper process for metal ion removal called chelators. These that bind to the metal ions which can then be removed through chemical and physical separation, yielding clean water However, compounds that are routinely used as heavy-metal chelators are non-biological and, therefore, not biodegradable. This is where compounds present in plants are helpful.

FLAVONOIDS

Pant flavonoids give colour and aroma pollowers and fruits, thereby facilitating pollination and seed dispersal by attracting animals. In addition to attractin beneficial organisms, plants produce such as pests ad por secondany metabolites gens. These tolerate environmental stresses such as extreme temperature, drought or salinity. Without these phytochemicals plants would not be able to protect themselves.

The chemical structure of flavonoid molecules allows them to chelate (bind to) heavy-metal ions, thereby changing the form of the metal so it is no longer toxic. This allows metal-hyperaccumulating plants to survive. However, not all plants are metal-hyperaccumulators, so using the flavonoid compounds rather than the plant isself as a source of heary metal chelators, is an environmentally friendly

\section{SCREENING FOR A STICKY}

\section{SOLUTION}

South Africa is a country with a huge 作 . on Earth. Pollution of water by heavy metals is particularly problematic in South Africa where mining is intense. Therefore, cleaning up this water to make it safe is a priority.

Luckay, together with his colleague, Hussein, have been funded by Stellenbosch University and the National Research Foundation or South Africa to search for native South African plants tha Wilh the useful for phytoremediation, With the knowlodge hat some plants We

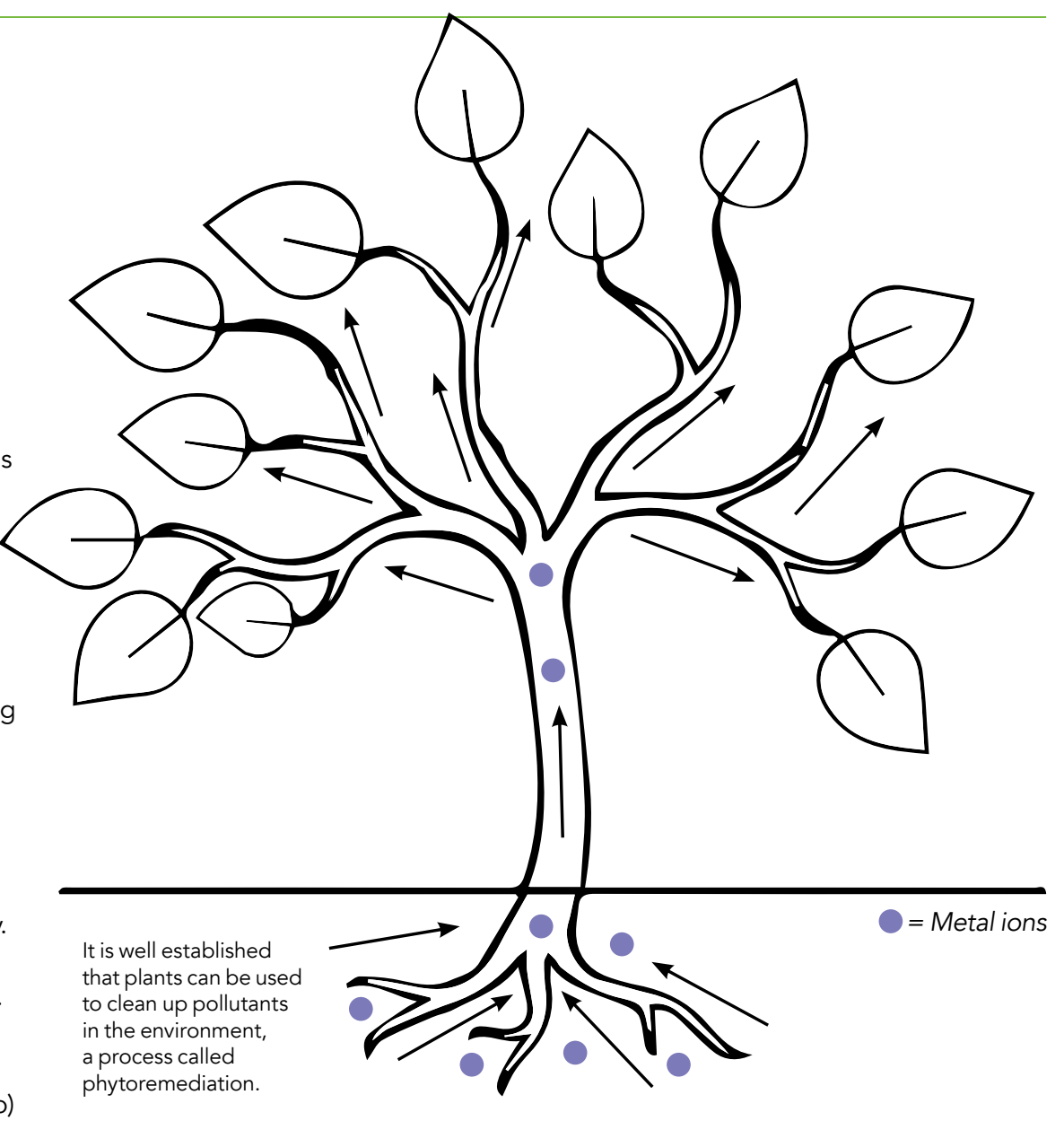

Findling green solutions to make water potable will not only help the environment, but also human health.

plants, both medicinal and non-medicinal, manganese, cadmium, and zinc in equal including the popular honeybush tea and metal-ion binding activity.

To start, the researchers obtained crude extracts from the chosen plants and ions from a cocktail solution containing iron, nickel, lead, copper, cobalt t, concentrations. The researchers found the hardly removed by crude extracts. The varying chemical nature of each heavymetal ion allowed preferential binding to the crude plant extracts. By diluting the

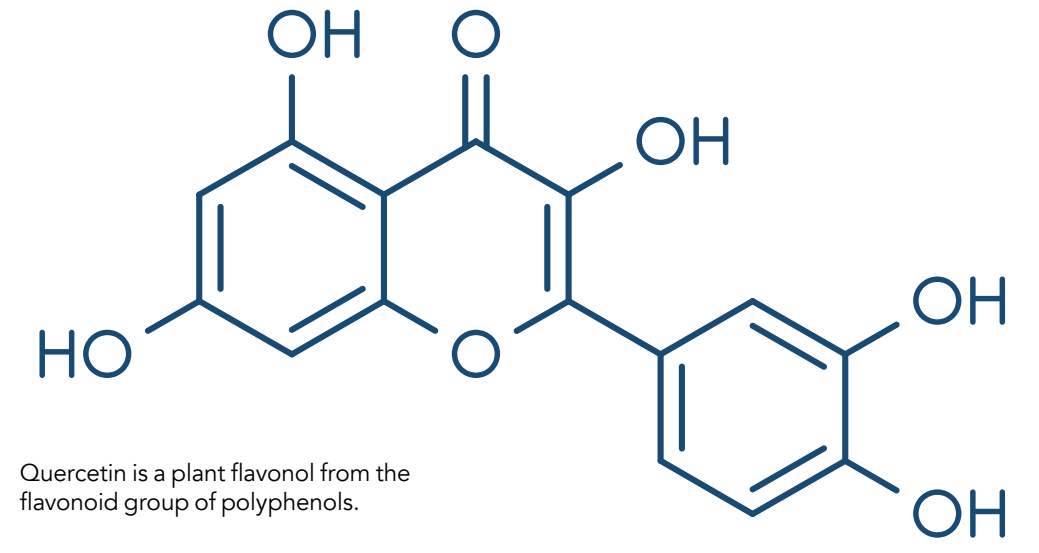


Removal of metal ions from the aqueous phase.

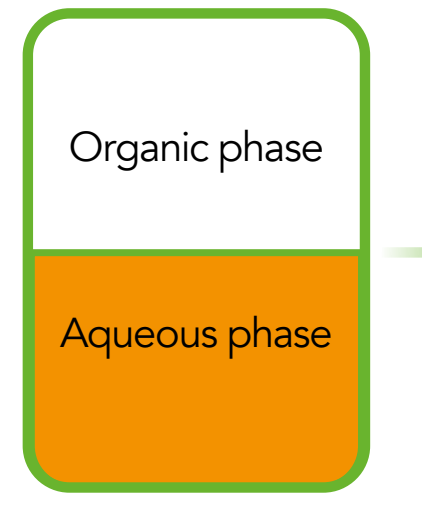

concentration of iron and lead ten-fold in the cocktail, the authors still found selective extraction of these two heary metal ions. Interestingly, they showed that the degree of acidity of the solution Having established that the plant crude extracts could separate certan heavy metals from a cocktail mixture, the team then went on to identify specific compounds present in these extracts that act as chelators.

\section{COLLATING CHELATORS}

Knowing that phenolics such as

Simple, green alternatives to tackle water pollution will be a small step towards a cleaner, healthier planet.

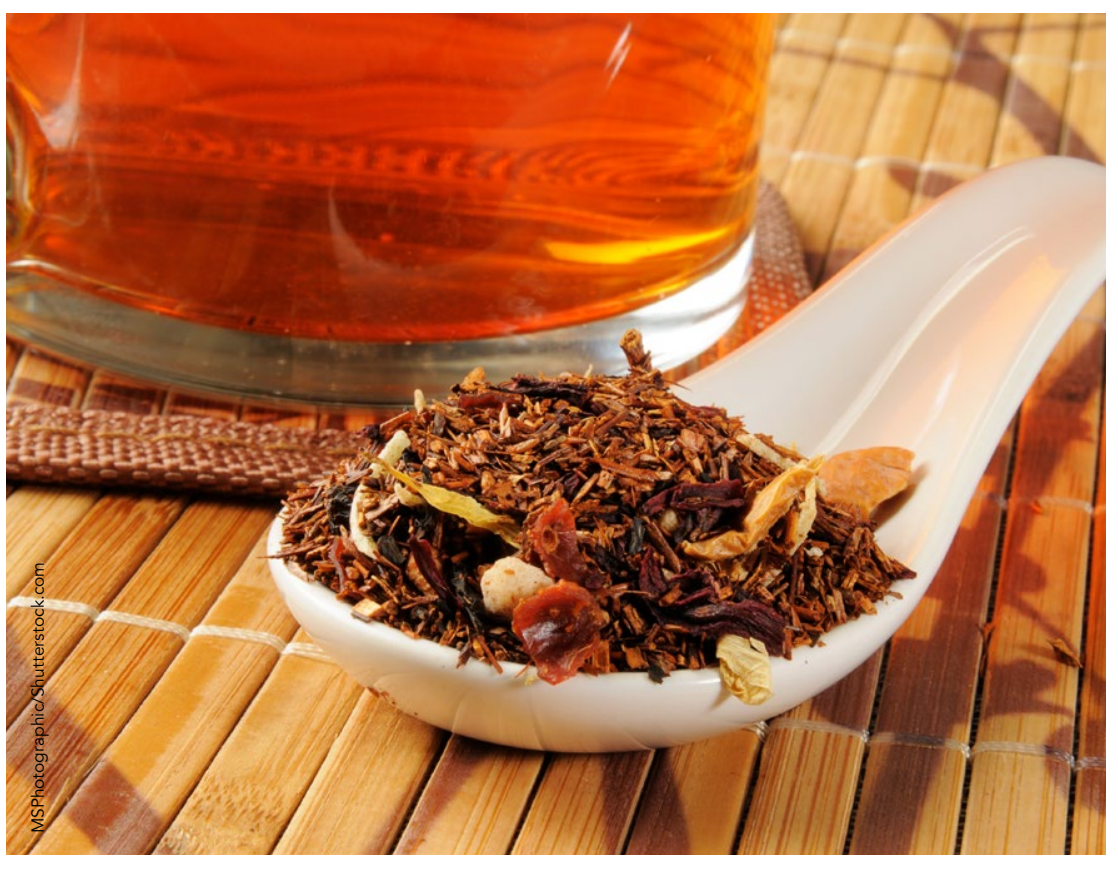

The native South African plants, including rooibos, was found to chelate metal ions.

flavonoids can chelate heavy metals, the authors identified phenolics from the crude mixtures using a technique mass spectrometry (LC MSIMS). This is a complex technique that involves separation and identification of passing a liquid with the unknown compound over a stationary colum that separates molecules either by size, charge, or affinity towards specific compounds. Using a molecular sieve in this manner, compounds separated Liquid chromatography (LC) invture.

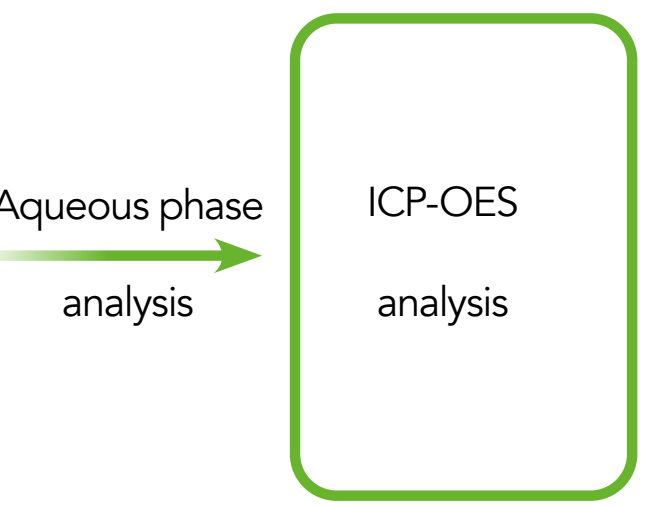

from a crude mixture are then fed into a mass spectrometer (MS). The molecules separated by LC are first onised (atom becomes positively or negatively charged) and then passed them according to their mass to charate ratio. The ions are then detected based on their charge, to produce a mass spectrum as output. In tandem MS, multiple ionisation events occurs increasing the sensitivity of detection of specific ions generated from a molecule. In this manner, the output is compared against a database of known mass spectra, to result in the identification of

Luckay and his team performed LC-MS/ MS to separate crude plant extracts, an identified phenolics from this mixture. Amongst the compounds identified, flavonoids such as quercetin and morin were identified in abundance. Quercet in plant species tested, suggesting tha its chemical properties offer the ability to bind to heavy metals. The team is currently studying the heavy-metal-

LOOKING FORWARD: GREEN CHELATION

Luckay and Hussein's study shows that crude plant extracts from all the studied plants are sufficient to extract heavy metals. Identification of green chelators of heavy metals provides a novel target to clean contaminated water, and scaling up these methods will be hugely beneficial. Such simple, green will be a small step towards a cleon healthier planet.

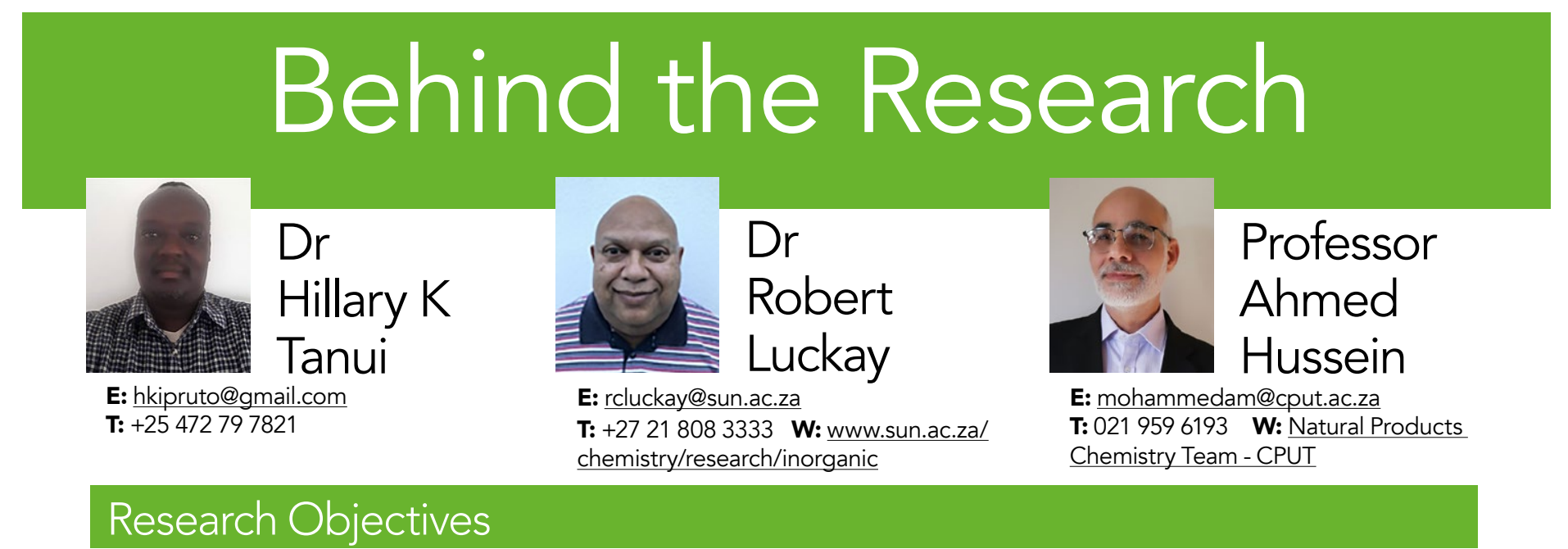

Research Objectives

Dr Luckay's research explores the use of plant flavonoids for removing heavy metals from contaminated wastewater

\section{Detail}

\section{Address}

Robert Luckay Science, Stell Chemistry \& Polymer Science, Stellenbosch University, Private
Bag X1, Matieland, Stellenbosch, 7602 . Bag XI, Matieland
South Africa

Professor Ahmed A Hussein Chemichy Department, office 2-33 Building, Cape Peninsula University of Technology, Bellville Campus, Private Bag X17 Bellville 7535, Cape Town

Bio

Dr Robert Luckay heads the Hydrometallurgy research group at
Stellenbosch University. His research

\section{References}

- Tanui, H, Hussein, A, Luckay, R, (2021) Selective removal of iron (III), lead (II) and copper (II) ions removal of iron (II), lead (II) and copper (II) ions ten South African plants: identification of plant phytochemicals. Int J Phytoremediation, 23, 755-764. doi.org/10.1080/15226514.2020.1857 332

Kasprzak, M, Erxleben, A, Ochocki, J, (2015) Properties and applications of flavonoid metal complexes. RSC Advances, 5, 45853-45877. -Anjum, A, Hasanuzzaman, M, Hossain, MA, et al, (2015) Jacks of metal/metalloid chelation trade in plants - an overview. Frontiers in Plant Science,

6(192). doil. $0.338 \% /$ pls. 2015.00192.

- Chibuike, G, Obiora, S, (2014) Heavy metal polluted soils: effect on plants and bioremediation methods. Appled and Enwionmental Tcience,

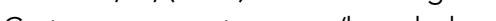
understanding-lcmsms/ interests include the separation of PGMs and base metal ions. This has important applications in the mining industry, and
also for 'urban mining', which involves recycling metal ions. One side project inselectively extracted by phytochemicals.
inter

Professor Ahmed Hussein is group a professor of organic chemistry in the Department of Chemistry at CPUT, Cape Town, South Africa. His research interes aspects and green nanotechnology- His main research focus is understanding the chemical and physical interaction(s) of different natural capping agents at
the interface of metal nanoparticles. The group also unlocks the potential of Cape
flora for new and potent natural bioactive compounds with health benefits.

Hillary K Tanui is a PhD candidate Polymer Science at Stellenbosch
Polic University. He holds an MSc in organic His interest is coordination chemistry. and phytochemistry targeting chemical remediation of water. His recent work has appeared in international peer

Funding National Research Foundation of South Africa, grant numbers 129234, 106055, an

\section{Personal Response}

Has this process been tested on heavy metal-contaminated waters from the environment, and if so, what can you tell us about your findings?

II This process has not yet been tested on environmental samples, samples high in iron, lead and copper concentrations since these crude phytochemicals work best with these metal ions.

f the process was scaled up, which would be most economical process that also yields better purification - using crude
extracts or pure flavonoids?

These flavonoids are not that expensive and the pure flavonoids would be the preferable substance to use. Our idea is to anchor could be used to bind and release metal ions. With this approach, the system could be used repeatedly for removal and release of toxic metal ions. 